\title{
High School Student Reactions to an Interdisciplinary Teaching Method in Agricultural Education
}

\author{
Grady Roberts $^{\mathrm{a}}$, Cacee Hilliard ${ }^{\mathrm{b}}$, Christelle Calixte ${ }^{\mathrm{a}}$ \\ ${ }^{a}$ University of Florida, ${ }^{b}$ Marion District Schools
}

Tomorrow's agricultural workforce will face challenges in the form of complex problems that transcend disciplinary boundaries, including food security. Addressing these complex issues requires professionals to work within and across disciplines in ways that may not have been required in previous generations. Teaching using an interdisciplinary approach may be one approach to helping students develop the skills needed to address these problems. The purpose of this study was to explore student reactions to being taught with an interdisciplinary teaching method in a secondary agricultural education context. Overall, students reacted favorably to this interdisciplinary teaching approach. Several student characteristics contributed to their reactions. Multiple aspects of the facilitation process also impacted student reactions, as did specific features of the interdisciplinary approach. The interdisciplinary teaching approach produced several learning outcomes beyond the technical concepts, including gaining new perspectives and critical thinking. Recommendations for teachers and recommendations for additional research are provided.

Keywords: agricultural education, interdisciplinary teaching, food security, learning outcomes, student reactions

\section{Introduction}

Tomorrow's agricultural workforce will face challenges in addressing complex issues such as food security, climate change, biodiversity preservation, water management conservation, and obesity. Labels like grand challenges (Beachy, 2010) and wicked problems (Rittel \& Webber, 1973) have been used to describe these complex interdisciplinary issues. Addressing these complex issues will require professionals to work within and across disciplines in ways that may not have been required in previous generations.

Thus, new ways of teaching need to be explored that allow for looking at issues from an interdisciplinary perspective. Agricultural educators at all levels must adapt the way they teach to help develop human capacity to tackle these issues (National Research Council, 2009). Researchers are being called to answer questions such as "what methods, models, and programs are effective in preparing people to solve complex, interdisciplinary problems (e.g. climate change, food security, sustainability, water conservation, etc.)?” (Roberts, Harder, \& Brashears, 2016, p. 10). Notably, through a 4 stage Delphi process, an expert panel ranked this as the highest ranked research question in the American Association for Agricultural Education 2016-2020 National Research Agenda (Roberts et al., 2016).

Complex issues, by definition, are complicated and potential solutions likely transcend multiple disciplines.
However, educational programs (K-12 and higher education) typically teach concepts in disciplinary silos called courses. There are examples of multidisciplinary efforts, but as Choi and Pak (2006) noted, these programs draw "on knowledge from different disciplines but stays within their boundaries" (p. 351). In contrast, an interdisciplinary approach "analyzes, synthesizes, and harmonizes links between disciplines coordinated and coherent whole” (Choi \& Pak, 2006, p. 351). It appears that an interdisciplinary approach may be best suited to help students gain skills to address these complex problems. This, however, may not be easy. Al Salami, Makela, and de Miranda (2017) noted a shift to interdisciplinary teaching "remains a significant problem" and "teachers need to develop both skills and attitudes towards interdisciplinary teaching” (p. 63).

A web search for examples of interdisciplinary teaching yielded a handful of interdisciplinary college degree programs and a small collection of multi-week modules targeted for undergraduate students. Resources and references appropriate for high school agricultural education were not found. As noted by McKim, Pauley, Velez, and Sorensen (2018), "SBAE [School-Based Agricultural Education] research has failed to provide a comprehensive, empirical model detailing the role of the teacher in facilitating interdisciplinary science and AFNR [Agriculture, Food, and Natural Resources] learning” (p. 179). Given the paucity of research in this area, the purpose of this study was to explore student reactions 
being taught with an interdisciplinary teaching method in a secondary agricultural education context.

\section{Theoretical Framework}

From a theoretical perspective, this study was designed and implemented based on constructivism and experiential learning theory, which assume that learners construct their own meanings based on their experiences (Kolb, 1984; Roberts, 2006; von Glaserfeld, 1996). Additionally, social cultural theory, which assumes learning occurs in a complex sociocultural environment, provided a basis for understanding the complex interactions that happen in a classroom (Vygotsky, 1978). This framework allowed the researchers to view learning as a process and view students as individuals participating in a learning community.

Interdisciplinary thinking is now recognized as an important goal for education. The National Research Council (2009) proposed graduates from the agricultural sciences should possess the skill to work across disciplines. The American Association for Agricultural Education (Roberts, et al., 2016) also echoed the importance of helping students develop skills to solve complex interdisciplinary problems. Looking specifically at the field of ecology, Bestelmeyer, Elser, Spellman, Sparrow, Haan-Amato, and Keener (2015) suggested that waiting until college to begin interdisciplinary education was too late. They advocated beginning in K-12 education. However, there is a paucity of research on interdisciplinary teaching in K-12 agricultural education (McKim et al., 2018).

Several studies examined the usage of interdisciplinary approaches in agriculture at the undergraduate education level. DiBenedetto, Lamm, Lamm, and Myers (2016) examined undergraduate agriculture students' attitudes toward interdisciplinary education. Using an interdisciplinary program focused on food security as the context, these researchers found both learning-goal orientation and performance-goal orientation influenced attitude toward interdisciplinary education. Mars (2015) explored student perceptions of an undergraduate, interdisciplinary entrepreneurship leadership program. He found this context to be an effective platform to bring together students from a great variety of academic majors and focus on a single issue. Levintova and Mueller (2015) examined an interdisciplinary class on global sustainability in order to discover how teaching with traditional lecture compared with active learning approaches. They learned that active learning strategies alone were not sufficient. Teaching foundational concepts using a traditional lecture and supplementing with active learning approaches that allowed students to apply those concepts proved most effective.

Although not necessarily interdisciplinary, researchers in agricultural education have often examined the impacts of using a problem-solving approach to teaching at the secondary level. Flowers and Osborne (1988) compared problem solving to the subject-matter approach and found no differences in student achievement. Boone (1990) also examined the impact of the problem-solving approach on student retention and achievement. He found student retention was greater when taught using the problem-solving approach, but student achievement was most impacted by characteristics of the teachers. Dyer and Osborne (1996a) explored whether student learning style impacted student achievement when taught using the problem-solving approach. They found field-neutral students had higher achievement than field-independent and field-dependent students when the problem-solving approach was used. In a related study, Dyer and Osborne (1996b) found fieldindependent learners had greater gains in problem solving ability than other students when taught using the problem-solving approach.

Other research has examined teacher adoption and discontinuance of novel teaching methods. At the secondary agricultural education level, Wilcox, Shoulders, and Myers (2014) looked at teaching using an interdisciplinary, socioscientific approach. They found that student excitement and engagement when taught using the novel approach impacted teachers' decisions to continue using the approach. Osborne and Hamzah (1989) examined the usage of problem-solving approaches by teachers in Illinois. They discovered that although teachers' lesson plans were written using a problem-solving approach, they typically employed a lecture-discussion approach.

Based on the available literature, the importance of interdisciplinary teaching is widely acknowledged. Interdisciplinary approaches at the undergraduate level can be beneficial for students, but balancing content and application is important. In secondary agricultural education, using teaching methods which use problems as the basis for teaching have shown positive impacts on students. Across all levels, teachers seem open to trying novel teaching approaches, but often struggle to continue these approaches without support. The current study fills an important gap in the literature by looking at interdisciplinary teaching in a secondary agricultural education context, specifically what students thought about the approach.

\section{Purpose}

The purpose of this study was to explore student reactions to being taught with an interdisciplinary teaching method in a secondary agricultural education context. Rockwell and Bennett (2004) proposed "reactions reflect participants' degree of positive or negative interest in topics addressed, their acceptance of activity leaders, and their attraction to the educational methods" (p. 6). Two research questions guided the study: 
1. How did students react to this teaching approach?

2. What should teachers consider when implementing this approach?

\section{Method}

Approach. As mentioned earlier, there did not appear to be an existing interdisciplinary teaching model appropriate for a short-term education program (i.e. unitlevel, 4 to 8 instructional hours) at the secondary level. The first step of this research was to select a general approach for interdisciplinary teaching. The work of Repko and Welch (2005) had been previously used to guide the implementation of a National Science Foundation project focused on interdisciplinary teaching. This approach was adapted for the current study and implemented using a 4-step process (Figure 1).

For the current study, the overarching problem was global food security. The United Nations Food and Agriculture Organization's (2008) publication An Introduction to the Basic Concepts of Food Security provided the framework. Disciplinary perspectives included: climate change, population growth, gender, poverty, and policy/trade. Considering these perspectives individually results in a disciplinary perspective. Considering them together lends to an interdisciplinary perspective. Students were organized into teams of three.
Each team selected a country from the U.S. government Feed the Future list and researched the conditions in each country related to each of the issues noted above.

The interdisciplinary approach was implemented by an outside researcher over a five-day period to three food science classes at a high school in Florida. The second researcher observed the implementation. The third researcher participated in data analysis. Days 1 to 4 consisted of a brief lecture (approximately 15 minutes) to give an overview of each disciplinary perspective and then approximately 30 minutes for students to use webbased resources to explore the current conditions related to the issue in their respective country. Student groups then synthesized their findings into a set of recommendations for their country. They presented their findings in the form of an oral presentation on the final day.

Research Design. The research questions of the study were answered using a case study design (Merriam, 2009; Stake, 1995). Collectively, the three classes studied were viewed as occurring in a bounded context and appropriately viewed as a case study (Merriam, 2009). A case study allows for examining a phenomenon in a given context but does not allow for wide-spread generalizability (Merriam, 2009). This was deemed an appropriate research method given the exploratory nature of this research.

1. Explain the rationale for an interdisciplinary approach.

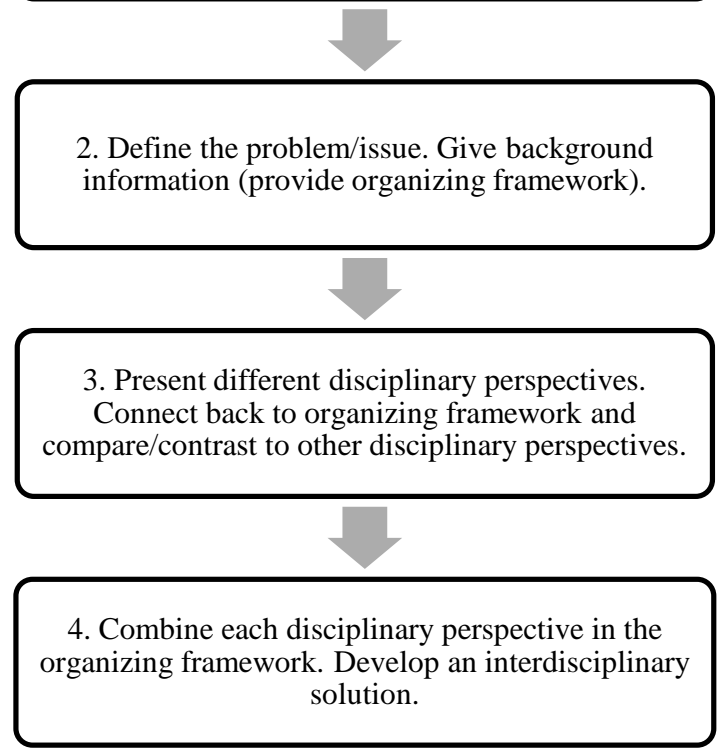

Figure 1. The Interdisciplinary Teaching Model (Adapted from Repko \& Welch, 2005). 
Table 1. Research Findings

\begin{tabular}{|c|c|c|c|}
\hline Themes & & & \\
\hline Student Characteristics & Facilitation & $\begin{array}{l}\text { Interdisciplinary } \\
\text { Approach }\end{array}$ & Learning Outcomes \\
\hline $\begin{array}{ll}\text { - } & \text { Nervousness } \\
\text { - } & \text { Learning Modalities } \\
\text { - } & \text { Prior Knowledge } \\
\text { - } & \text { Accountability }\end{array}$ & $\begin{array}{ll}\text { - } & \text { Lecturing } \\
\text { - } & \text { Structure } \\
\text { - } & \text { Balance } \\
\text { - } & \text { Reviewing } \\
\text { - } & \text { Assessment } \\
\text { - } & \text { Oral Presentations } \\
\text { - } & \text { Time }\end{array}$ & $\begin{array}{ll}\text { - } & \text { Data Sources } \\
\text { - } & \text { Research } \\
\text { - } & \text { Disciplinary } \\
& \text { Connections }\end{array}$ & $\begin{array}{ll}\text { - } & \text { New Perspectives } \\
\text { - } & \text { Critical Thinking }\end{array}$ \\
\hline
\end{tabular}

From an epistemological perspective, we were interested in understanding this phenomenon through the shared lived experiences of the learners. Thus, a social constructionist approach was taken when designing and implementing this research (Crotty, 1998).

Data Collection. Overall, approximately 60 students experienced this teaching approach as a part of their normal class activities. All students were invited to participate in the focus groups and were provided with parental consent and student assent forms. Research participants consisted of all students who returned both signed forms. In total, fourteen students participated in the focus groups, including 7 students from class 1,4 students from class 2, and 3 students from class 3 . Separate focus groups were conducted with participants from each class during normal class time at the conclusion of the intervention. Using a semi-structured approach, the following questions guided the focus groups:

1. In general, what did you like and dislike about the experience?

2. How do you think hearing about many different ways at looking at a single issue impacted your learning?

3. How do you think this experience will impact the way you approach learning about other topics in other classes?

4. In your mind, what would make this approach even more effective?

5. What advice would you give a teacher who wishes to use this interdisciplinary teaching approach?

6. Do you have any additional comments you would like to express on the topic?

Data Analysis. Based on our social constructionist approach, first cycle coding was done line by line using an open coding technique to identify initial themes by the third researcher (Merriam, 2009; Saldaña, 2016). This inductive process allowed the perspectives of participants to drive the understanding of the phenomenon through connecting similar thoughts expressed by different participants. Following the discovery of initial codes, the researcher used axial coding to organize codes into themes and sub-themes based on patterns in the data, allowing for better interpretation of the data (Saldaña, 2016; Strauss \& Corbin, 2008). The lead researcher reviewed the data analysis. Results are presented in the form of themes and sub-themes. Quotes are used to provide a voice to participants.

\section{Trustworthiness and Rigor}

This research was conducted by a three-member team, which allowed for multiple steps to ensure trustworthiness and rigor. First, the lead researcher and second researcher had prolonged engagement with the research participants (Lincoln \& Guba, 1985). The implementation and data collection occurred over an eight-day period. Second, the lead researcher kept a reflexive journal to provide an audit trail (Lincoln \& Guba, 1985). Third, the second researcher observed the implementation, but did not participate in data analysis. This allowed for peer-debriefing during and after the implementation (Lincoln \& Guba, 1985). The second researcher also reviewed the data analysis to verify results were consistent with her observations as a form of triangulation (Lincoln \& Guba, 1985). The third researcher, not present for the implementation, conducted the data analysis. Collectively, this three-researcher approach allowed for establishing the trustworthiness of this research and minimizing the impacts of any biases.

Findings. Four themes emerged from focus group and field note data. They included: student characteristics, the facilitation process, the interdisciplinary approach, and learning outcomes. Multiple sub-themes were also identified. A summary of the findings is presented in Table 1.

Student Characteristics. Nervousness. The students identified situations which may either hinder or enhance their learning. Their own nervousness, particularly during oral presentations, created confusion regarding the message that they were trying to convey to the rest of the class: "I feel like when students are presenting, sometimes they often get nervous and stuff, so then who they're presenting to gets confused on what 
they're talking about” (focus group 3). This situation, according to students in two of the focus groups, seemed to be an important component to consider when using oral presentations for teaching content. Observations of the student presentations confirmed nervousness on the part of many students (field notes, day 4).

Learning modalities. Student preferences for learning in certain ways was also pointed out during two focus groups. Some would prefer "some visual content maybe, like some pictures of what we're researching" (focus group 2). They proposed the importance of using handouts, both as a way of facilitating the instruction: "I would say have a piece of paper with all the PowerPoints, so kids won't have to constantly look up and type in," (focus group 1) and as a means to help visual learners take notes: "I'd rather take notes on something that somebody's presenting to me” (focus group 3). Others however, qualify themselves as hands-on learners: "I'm a hands-on learner" (focus group 2), and therefore love the idea of exploring the content themselves: "It's a lot better for you to explore and see what you can learn from it" (focus group 1). Classroom observations supported that student attentiveness varied based on the specific activity (field notes, days 2 and 3).

Prior knowledge. Learners' prior knowledge may also influence how they assimilate knowledge, as mentioned in one focus group: "for the most part, I knew what to do, and I really didn't have that much trouble with it" (focus group 2). The importance of an appropriate level of prior knowledge was also noted by the lead researcher (field notes, day 4). Students who appeared to have a broader understanding of the concept were able to more quickly begin the activity and took less prompting from the teacher (field notes, days 1, 2, 3).

Accountability. Personal accountability seems to be the most influential student characteristic that determined success, as all three focus groups mentioned it. A student's accountability was very noticeable during group work, when they acknowledge: "I know I'm accountable for what happened" (focus group 1). Student accountability was demonstrated with the level of engagement or effort they dedicated to the work, for example: "If you were diligently working, you had put it together" (focus group 3). Students also expressed the importance of timeliness in the completion of assignments, for example: “One thing I didn't like, and it's not the strategy of teaching or the teacher in itself, it's that some kids, for example, won't have presentations done on time" (focus group 3). The idea of accountability was further emphasized as students chose their team partners for the group work. One student admitted, "I guess that relies more on the students than on the teacher" (focus group 3). The idea of choice and personal accountability was also realized through the way the project was implemented. One participant pointed out the teacher's vagueness when they were doing research on the website and observed, "that left room for us to use our discretion on how we wanted to approach things" (focus group 3).
Facilitation. Lecturing. The most frequent subtheme focused on lecturing, which emerged in all focus groups and many times throughout each one of them. There were many ways this idea was expressed: "I would advise them [teachers] to make sure that students understand the material" (focus group 2), "you should definitely teach them" (focus group 2), "you explained it to us more in a way we could understand" (focus group 1), and "give "em a presentation" (focus group 1). The terms: "explain," "presentation," and "understand” stood out as some of the ways participants referred to lectures. Students appreciated the length of the lectures. When asked about advice for other teachers, a student said "for instance, the 10-20-minute lectures” (focus group 3) should be used more often. Lead researcher observations concurred with the value of the short lectures (field notes, day 2).

Structure. Focus group participants appreciated structure in the form of personal attention, overall guidance, and directions. Students appreciated that they were given "specific websites to go to" (focus group 1). The also liked how the teacher "walked around and went to each individual group” (focus group 2). They also valued the direction given because they "know what to do, much better than we would just doing it by ourselves" (focus group 3). The facilitation process is simplified when there are connections between concepts. Students in all three focus groups appreciated that "everything kept connecting back to where we began" (focus group 3) or that they had a clearer understanding after making connections, for example: "I thought they were just sort of minor topics, not that they were rooted in so many issues" (focus group 2). The importance of clear directions was observed by the lead researcher (field notes, day 1). Overall, the process participants preferred was summed up by one participant as: "You explained it to us, gave us the opportunity to go research it, and then present what we had" (focus group 3).

Balance. Students appreciated the balance between lecture and more participatory methods in general. Participants thought "it was a pretty decent balance" (focus group 3) referring to lecture and oral presentations or "I think it was a good balance" (focus group 2) when talking about time spent lecturing to "teach us the information" (focus group 2) followed by "hands-on application" (focus group 2) to reinforce. However, some would have preferred to add an element of whole class discussion; they thought "that just a few minutes of class discussion would have been better" (focus group 2) to facilitate their understanding of the differences and similarities between the groups' assignments.

Reviewing. Students also seemed to appreciate reviewing concepts throughout the days of instruction (field notes, days 1, 2, 3). Two of the groups mentioned reviewing concepts as beneficial to their understanding to "make sure you review everything from previous day" (focus group 1) or as a type of constant debriefing throughout class facilitation. One participant stated, "I 
like how much you reviewed every time we went into a new section" (focus group 1).

Assessment. The idea of assessment and grades emerged from all three focus groups. Sometimes assessment was mentioned as a form of formative feedback on progress in class activities: "I also liked the feedback you gave us when we were working on it" (focus group 2). However, participants were mostly concerned about how grading was tied to all the activities, particularly the oral presentations. Because the lead researcher was not the typical teacher, there was some confusion about how this activity might count, with students wondering "if it were for an exam or something like that" (focus group 3). Grading is so important to them that the need for a rubric was also mentioned a few times, for example: "I think you should definitely give rubrics... if the teacher was gonna grade" (focus group 2). They even tied the rubric with time management: "I think also if we had a rubric, it would help us manage our time better" (focus group 2), because they would know which part of the assignment to focus on based on the grading scale. Student concern about grades was also noticed by the lead researcher, especially on the presentation day (field notes, day 5).

Oral presentations. Students appreciated the oral presentations. However, as noted earlier, student concerns with grading were expressed when some group members had been absent, leaving students to feel as if they "have to go learn it on your own" (focus group 3), which they considered double work and inefficient. On the other hand, oral presentations as a whole were viewed positively by participants, and they thought it may help students practice their communication skills "allowing them to get that job experience of maybe having to speak at a conference one day" (focus group 3). Concerns about absent group members was also noted by the lead researcher (field notes, days 3, 4).

Time. When asked about the time spent on the assignments, most groups felt it was sufficient but only because of the weekend days, which "gave us the opportunity to work on it during the weekend" (focus group 1). Students in another focus group would have preferred an additional day. A participant even proposed that "the project has to be specifically in those five days" (focus group 1). However, most of them valued the time "to absorb the information" (focus group 1), which was brought up a few times, because "most teachers don't give us that time to absorb it” (focus group 1). They also mentioned time management when it came to classroom control during some of the research assignments: "it'll take some more time to quiet them down" (focus group 2), therefore it was more efficient to give them all the research time at once rather than in chunks. Research was also tied to time, as students realized it is not a fast process because "it did take us a while to find our research online” (focus group 3). Ultimately participants valued the pace of instruction without losing depth: "I feel like it was done quickly, but it was done very thoroughly” (focus group 3). The lead researcher wondered early in the process if students were "getting the key concepts" (field notes, day 2), but was satisfied in the end that most students had gained a better understanding of food security (field notes, day 5).

Interdisciplinary Approach. Data sources. Students were directed to a series of websites to gather data. Websites included sites from the United Nations, the CIA Factbook, the Global Food Security Index, and the World Bank. The data sources caused some confusion for students. Teachers should perhaps avoid complicated tools, as this was discussed quite a few times in two of the focus groups. The website they were using for information was not easy to comprehend, which seemed to have hindered student learning and concentration on the subject, for example: "I got very confused when trying to figure that out" (focus group 3). It was also portrayed as containing "a lotta information" (focus group 1) and too much to handle properly: "I just felt overwhelmed" (focus group 1). The challenges with obtaining relevant information from the websites was also noted by the lead researcher (field notes, days 2, 3).

Research. Many students appreciated the research component of the class activities. They thought if you are "doing the research yourself" (focus group 3), it helps them "take in the knowledge more" (focus group 3). However, they like the balance between lecture and research and it seems that they prefer to clearly understand what it is they need to investigate before doing the research. One student shared, "I like how you taught us, and then you made us do our own research" (focus group 3). One student shared that rather than starting with a lecture with all the information, doing the research "made us learn more" (focus group 3). Another student elaborated: "it's a lot better for you to explore and see what you can learn from it” (focus group 1). However, many of the participants appreciated having the lecture first.

Disciplinary connections. Students made many connections with the concepts learned. Students referenced world history and sciences classes. One student thought, "World history really connected to what we were talking about" (focus group 1). Others think it to be applicable to any other class they may take: "You can apply every single class that you have taken in the past to that certain subject” (focus group 1). Students also thought about applications in their future lives, with statements like "you can apply that to everyday life, not just in a career" (focus group 3). The lead researcher noted several observations of "aha moments" (field notes, day 2) and references to linkages with other classes (field notes, days $1,3,4)$.

Learning Outcomes. New perspectives. All focus groups discussed gaining new perspectives about something they may have previously ignored. Statements like "we actually learned something new from different country" (focus group 1) and "you can look at something one way, and it can come at you nine different ways" 
(focus group 3) showed new perspectives from students. They also talked about how it "opened up my eyes as a student” (focus group 3) "about what's happening in the world” (focus group 1). It even helped them understand how they live in the United States as compared to other countries which "definitely puts things into perspective" (focus group 2). The prevalence of "eye-opening” experiences was noted by the lead researcher on multiple days (field notes, days 2, 3, 4).

Critical thinking. Students expressed evidence of critical thinking in their comments. Understanding the connections between population growth and potential for food insecurity were conveyed in statements like "population growth [can produce a] higher risk of hunger and starvation" (focus group 1). Some even referred to having more appreciation for their own conditions, saying "it made me feel more appreciative of what I have every day" (focus group 2). Another student said, "We no longer just take food for granted” (focus group 2). A student in one focus group seemed to be emotionally impacted, acknowledging that "we're so privileged, it's heartbreaking I suppose" (focus group 2). The lead researcher observed varying levels of critical thinking in the final presentations, noting "some groups really got it" (field notes, day 5).

\section{Conclusions and Discussion}

Several conclusions can be drawn about this teaching method with this particular group of students. Overall, students reacted favorably to this interdisciplinary teaching approach. Discussion is organized around the themes of Student Characteristics, Facilitation, Interdisciplinary Approach, and Learning Outcomes.

Student Characteristics. Data revealed several student characteristics which contributed to their reactions to this interdisciplinary teaching approach. Certain aspects of the approach, namely the oral presentation, made students nervous. Students appreciated the variability in activities which appealed to multiple learning modalities. The amount or prior knowledge impacted student reactions. Finally, personal accountability was important to learning.

These findings are consistent with theory and prior research. The importance of all learning building in prior knowledge is consistent with experiential learning theory (Kolb, 1984; Roberts, 2006). Variability in learning activities has long been recognized as an important feature of effective teaching (Rosenshine \& Furst, 1971). Dyer and Osborne (1996a) had previously discovered certain student characteristics impacted learning.

Before implementing a similar interdisciplinary teaching approach, teachers should consider the characteristics of their students. Of considerable importance is the prior knowledge of students. If students do not have requisite knowledge, more time should be devoted to basic understandings of key concepts.

Facilitation. Multiple aspects of the facilitation impacted student reactions. Students appreciated the short lectures and the overall structure of the approach. They enjoyed the balance between lecture and application. They especially liked the frequent reviewing that occurred each day. Students expressed concerns about assessment, indicating a desire for grading rubrics. They were especially concerned about the oral presentations but appreciated the skills they gained. The amount of time allocated for activities was of concern for some students.

Results of this study proved consistent with theory and previous research. The importance of providing foundation knowledge to students was echoed by Levintova and Mueller (2015). Frequent reviewing throughout the learning process is consistent with experiential learning theory (Kolb, 1984; Roberts, 2006).

Teachers using an interdisciplinary teaching approach similar to this should consider limiting the amount lecturing to provide more time for discovery. If websites are used as data sources, care should be taken to select sites in which data is easily accessible and understandable.

Interdisciplinary Approach. Specific features of the interdisciplinary approach also influenced student reactions. Students expressed some frustrations about the websites used to find data. They did, however, value the research process. Students also made connections between the concepts learned and their other coursework.

These findings are similar to prior research. Student appreciation for inquiry in the agriculture curriculum was previously documented by Thoron and Burleson (2014). Connections with other courses was consistent with the work of Mars (2015).

When implementing a similar interdisciplinary teaching approach, teachers should be explicit in the disciplinary connections. As students expand their interdisciplinary understandings, the teacher should help draw connections back to the core disciplines (history, science, etc.).

Learning Outcomes. The interdisciplinary teaching approach produced several learning outcomes beyond the technical concepts. Students reported gaining new perspectives they had not realized before. Students also demonstrated the ability to think critically about complex subjects.

These results are similar to other research. The importance of agricultural educators helping students develop new perspectives was also echoed by McKim, Velez, Lambert, and Balschweid (2017). Critical thinking has also been recognized as an important skill for agriculture students (Easterly, Warner, Myers, Lamm, \& Telg, 2017). 
Teachers who wish to use a similar interdisciplinary teaching approach should establish clear expectations for evaluating student learning and clearly communicate those expectations to students. Additionally, grading rubrics should be used when appropriate.

\section{Recommendations for Future Research}

This study was exploratory in nature and thus yields many opportunities for future research. These include:

- The approach should be further tested with other students, in other topic areas, and at other academic levels.

- Aside from student reactions, researchers should measure actual learning.

- Additional quantitative assessments of student critical thinking could also be used to test this approach.

- Researchers should also examine the impacts on performance in disciplinary classes as a result of learning from an interdisciplinary approach.

- This approach requires teachers to do things differently. Additional research could determine teacher perceptions of this approach.

- $\quad$ The long-term impacts on students taught using this approach should be examined. Ultimately, do students taught this way go on to make a difference in the complex issues noted in the introduction?

\section{References}

Al Salami, M. K., Makela, C. J., \& de Miranda, M. A. (2017). Assessing changes in teachers' attitudes toward interdisciplinary STEM teaching. International Journal of Technology and Design Education, 27(1), 63-88. https://doi.org/10.1007 /s10798-015-9341-0

Beachy, R. (2010, May). Research at the USDA: Addressing societal grand challenges. AAAS Policy Forum 2010, Washington, DC.

Bestelmeyer, S. V., Elser, M. M., Spellman, K. V., Sparrow, E. B., Haan-Amato, S. S., \& Keener, A., (2015). Collaboration, interdisciplinary thinking, and communication: New approaches to K-12 ecology education. Frontiers in Ecology and the Environment, 13(1), 37-43. https://doi.org/10.1890 /140130

Boone, Jr., H. N. (1990). Effect of level of problem solving approach to teaching student achievement and retention. Journal of Agricultural Education, 31(1), 18-26. https://doi.org/10.5032/jae.1990 .01018

Choi, B. C. K., \& Pak, A. W. P. (2006). Multidisciplinarity, interdisciplinarity and transdisciplinarity in health research, services, education and policy: 1 . Definitions, objectives, and evidence of effectiveness. Clinical \& Investigative Medicine, 29(6), 351-364.
Crotty, M. (1998). The foundations of social research: Meaning and perspective in the research process. London, England: Sage.

DiBenedetto, C. A., Lamm, K. W., Lamm, A. J., \& Myers, B. E. (2016). Examining undergraduate student attitude towards interdisciplinary education. Journal of Agricultural Education, 57(1), 167-178. https://doi.org/10.5032/jae.2016.01167

Dyer, J. E., \& Osborne, E. (1996a). Effects of teaching approach on achievement of agricultural education students with varying learning styles. Journal of Agricultural Education, 37(3), 43-51. https:// doi.org/10.5032/jae.1996.03043

Dyer, J. E., \& Osborne, E. W. (1996b). Effects of teaching approach on problem solving ability of agricultural education students with varying learning styles. Journal of Agricultural Education, 37(4), 38-45. https://doi.org/10.5032/jae.1996 .04038

Easterly, III, R. G., Warner, A. J., Myers, B. E., Lamm, A. J., \& Telg, R. W. (2017). Skills students need in the real world: Competencies desired by agricultural and natural resources industry leaders. Journal of Agricultural Education, 58(4) 225-239. https://doi.org/10.5032/jae.2017.04225

Flowers, J., \& Osborne, E. W. (1988). The problem solving and subject matter approaches to teaching vocational agriculture: Effects on student achievement and retention. Journal of the American Association of Teacher Educators in Agriculture, 29(1), 20-26. https://doi.org/10.5032/jaatea.1988 .01020

Food and Agriculture Organization. (2008). An introduction to the basic concepts of food security. Rome, Italy: UN FAO.

Kolb, D. A. (1984). Experiential learning: Experience as the source of learning and development. Upper Saddle River, NJ: Prentice Hall.

Levintova, E. M., \& Mueller, D. W. (2015). Sustainability: Teaching an interdisciplinary threshold concept through traditional lecture and active learning. The Canadian Journal for the Scholarship of Teaching and Learning, 6(1), Article 3. https://doi.org/10.5206/cjsotl-rcacea .2015.1.3

Lincoln, Y. S., \& Guba, E. G. (1985). Naturalistic inquiry. Beverly Hills, CA: Sage Publications.

Mars, M. M. (2015). Interdisciplinary entrepreneurial leadership education and the development of agricultural innovators. Journal of Agricultural Education, 56(3), 178-194. https://doi.org/10.5032 /jae.2015.03178

McKim, A. J., Pauley, C. M., Velez, J. J., \& Sorensen, T. J. (2018). Interdisciplinary learning opportunities in agriculture, food, natural resources, and science: The role of the teacher. Journal of Agricultural Education, 59(2), 179-196. https://doi.org/10.5032 /jae.2018.02179 
McKim, A. J., Velez, J. J., Lambert, M. D., \& Balschweid, M. A. (2017). A philosophical review of science and society within agricultural education. Journal of Agricultural Education, 58(2), 98-110. https://doi.org/10.5032 /jae.2017.02098

Merriam, S. B. (2009). Qualitative research: A guide to design and implementation. San Francisco, CA: Jossey-Bass.

National Research Council. (2009). Transforming agricultural education for a changing world. Washington, DC: National Academies Press.

Osborne, E. W., \& Hamzah, R. (1989). Use of problem solving teaching among secondary agriculture teachers in Illinois. Journal of Agricultural Education, 30(3), 29-36. https://doi.org/10.5032 /jae.1989.03029

Repko, A. F., \& Welch, J. L., IV. (2005). Interdisciplinary practice: A student guide to research and writing. Boston, MA: Pearson.

Rittel, H. W. J., \& Webber, M. M. (1973). Dilemmas in general theory of planning. Policy Sciences, 4, 155169. https://doi.org/10.1007/bf01405730

Roberts, T. G. (2006). A philosophical examination of experiential learning theory for agricultural educators. Journal of Agricultural Education, 47(1), 17-29. https://doi.org/10.5032/jae.2006 .01017

Roberts, T. G., Harder, A., \& Brashears, M. T. (Eds). (2016). American Association for Agricultural Education national research agenda: 2016-2020. Gainesville, FL: Department of Agricultural Education and Communication.

Rockwell, K., \& Bennett, C. (2004). Targeting outcomes of programs: A hierarchy for targeting outcomes and evaluating their achievement. Lincoln, NE: Department of Agricultural Leadership, Education and Communication.

Rosenshine, B., \& Furst, N. (1971). Research on teacher performance criteria. In B.O. Smith (Ed.), Research in Teacher Education (pp. 37-72). Englewood Cliffs, NJ: Prentice Hall.

Saldaña, J. (2016). The coding manual for qualitative researchers (3rd ed.). Thousand Oaks, CA: Sage.

Stake, R. E. (1995). The art of case study research. Thousand Oaks, CA: Sage.

Strauss, A., \& Corbin, J. (2008). Basics of qualitative research: Grounded theory procedures and techniques. (3rd ed.). Newbury Park, CA: Sage.

Thoron, A. C., \& Burleson, S. E. (2014). Students' perceptions of agriscience when taught through inquiry-based instruction. Journal of Agricultural Education, 55(1), 66-75. https://doi.org/10.5032/jae .2014 .01066

von Glasersfeld, E. (1996). Introduction: Aspects of constructivism. In C. T. Fosnot (Ed.), Constructivism: Theory, perspectives, and practice (p. 3-7). New York, NY: Teachers College Press, Columbia University.
Vygotsky, L. S. (1978). Mind in society: The development of higher psychological processes. Cambridge, MA: Harvard University Press.

Wilcox, A.K., Shoulders, C.W., \& Myers, B.E. (2014). Encouraging teacher change within the realities of school-based agricultural education: Lessons from teachers' initial use of socioscientific issues-based instruction. Journal of Agricultural Education, 55(5), 16-29. https://doi.org/10.5032/jae.2014 .05016 